\title{
Las voces del Cedid: niñas y niños abriéndose camino hacia la participación
}

\author{
The voices of Cedid: girls and boys making their way to participation
}

\author{
Shirley Yisela Pulido Velásquez¹, Paula Jimena González Rodríguez²
}

Para citar este artículo: Pulido, S. Y., González, P. J. (2020).

Las voces del Cedid: niñas y niños abriéndose camino ha-

cia la participación. Infancias Imágenes, 19(2), 143-146

\section{Resumen}

El escenario de la presente reflexión es la escuela. En específico, una de las instituciones públicas de la ciudad de Bogotá, en la cual se indagó sobre las prácticas, momentos, modos y formas como los niños y las niñas se expresan; al mismo tiempo, la manera en que participan en la toma de decisiones dentro de esta. Es así como a través del análisis de las significaciones imaginarias sociales instituidas e instituyentes veremos que lentamente emergen las voces de la infancia como un acto revolucionario para toda la comunidad educativa. Pero, sobre todo, cómo se van transformando las dinámicas, las relaciones y sujetos en torno al fortalecimiento de su autonomía y conciencia colectiva.

Palabras clave: infancia, participación, construcción colectiva, significaciones imaginarias, escuela.

1 Licenciada en Pedagogía Infantil. Especialista en Infancia, Cultura y Desarrollo. Magíster en Infancia y Cultura, Universidad Distrital Francisco José de Caldas. Maestra en la Secretaría Distrital de Educación. Correo electrónico: yiselapulido@gmail.com

2 Socióloga, Universidad Santo Tomás. Especialista en Infancia, Cultura y Desarrollo. Magíster en Infancia y Cultura, Universidad Distrital Francisco José de Caldas. Asesora social para el programa Tecnokids. Correo electrónico: p.jgonzalezcpe@gmail.com 
La educación es un acto de amor, por tanto, un acto de valor. No puede temer el debate, el análisis de la realidad; no puede huir de la discusión creadora, bajo pena de ser una farsa.

Paulo Freire

Durante el proceso de puesta en marcha de la investigación denominada "Significaciones imaginarias sociales sobre participación de niños y niñas en la escuela para la cultura de paz. Semillero de participación las voces del Cedid" se develó un sin número de prácticas complejas e instituidas que dan cuenta de una problemática evidente en la escuela: las niñas y los niños no son tenidos en cuenta para la construcción de su entorno escolar, salvo en los casos en los que la participación es individualizada o cuando aparece para reafirmar la autoridad del docente (González y Pulido, 2019).

Hoy en la escuela la participación de las y los estudiantes es considerada importante desde el punto de vista normativo, mediante la figura del gobierno escolar o de algunos gestos como levantar la mano para pedir la palabra. Sin embargo, es una realidad que niños, niñas, así como las y los jóvenes estudiantes, no tienen gran incidencia dentro de en las decisiones que se toman en el cotidiano escolar, ya que resulta meramente nominal la creación de los consejos estudiantiles o la elección de los representantes de curso. Se encuentran sin espacios reales dentro de la apretada jornada escolar, en donde se encuentren como colectivo para emprender tareas que incidan en su realidad inmediata o sin la posibilidad de encontrar a una persona adulta que acompañe estos procesos, desligados de sus propias obligaciones contractuales como docente.

Esto nos lleva a entender que las significaciones imaginarias que se han elaborado a lo largo de la historia sobre el sujeto (niño o niña) que mantienen la idea de que las infancias no tienen criterio suficiente para tomar decisiones a su corta edad, que carecen de capacidad reflexiva sobre su propia realidad (debido a su poca experiencia o por cómo se estableció con una significación imaginaria de la edad moderna) y que la niñez es la etapa de vida en la que se prepara al sujeto para el adulto que será.
Todo lo anterior da por descartado que el infante es un sujeto protagónico (Rincón, 2013).

Partiendo de estos hallazgos surge el momento preciso para abrir en la escuela un espacio en el que niños y niñas se hicieran conscientes de sus posibilidades para construir su camino en medio de las significaciones imaginarias de los adultos, de los límites de horarios creados para la exclusividad de las aulas, de las prioridades de maestros sobre los saberes indicados, de los miedos de la familia por no cumplir con los deberes (en medio incluso de sus propias dificultades para creer en sí mismos) y, sobre todo, del miedo de los adultos por perder su autoridad.

Cabe anotar que cada uno de dichos obstáculos fue sorteado autónomamente por los y las participantes del semillero, reconociéndose como sujetos capaces de actuar en colectivo y por el bienestar común. Líderes y lideresas que al culminar el año mostraron a la comunidad educativa que, siendo niños y niñas (desde grado primero hasta grado quinto), habían logrado establecer una propuesta contundente en la que su contexto escolar tendría la posibilidad de transformar sus relaciones entre pares $y$, en definitiva, las relaciones con todas aquellas personas con las cuales interactúan dentro de su territorio escolar. De todo ello emergieron significaciones imaginarias instituyentes, posibilitadoras de los cambios necesarios en la escuela.

Desde la conformación del semillero de participación Las voces del Cedid (con las y los estudiantes representantes de curso de los grados de primaria de la jornada tarde) se planteó rastrear las partículas más pequeñas de las significaciones imaginarias sobre participación. Entre estas: el legein (pensar) y el teukhein (actuar); las cuales fueron analizadas durante toda la aplicación metodológica, permitiéndonos (y aún nos ofrece), el reconocimiento del sujeto niño y niña como actor protagónico en la transformación de su propia realidad; incluso, permitió hacer una introspección del sujeto adulto y su rol dentro de ese proceso. Además de proporcionarnos herramientas que nos permitieron actuar en consecuencia y coherencia con una escuela con relaciones horizontales, armónicas, significativas y colectivas. 


\section{Luego del proceso de investigación:}

Parte de los resultados de la investigación fue la misma propuesta del semillero, en la cual se estableció como medio importante para la divulgación de sus ideas la creación del programa radial escolar, ya que gracias al vínculo generado con algunos de los participantes y Tripulantes de la Cátedra Unesco y la Universidad Distrital Francisco José de Caldas, ellos y ellas tuvieron la oportunidad de realizar una visita a las instalaciones de la emisora universitaria e incluso de participar de la creación de contenido radial en vivo y en diferido.

Como producto de lo anterior, surgió la posibilidad de ampliar dicha experiencia a otros niños y niñas, estableciéndose un convenio entre la Cátedra Unesco y el colegio Cedid San Pablo de Bosa para la realización de un taller radiofónico en el que se beneficiaron alrededor de 40 estudiantes de diferentes niveles y que permitió la creación de contenido para el programa Tripulantes. Esta experiencia se divulgó en el blog de la institución educativa como un logro interinstitucional y, además, como una posibilidad de continuar abriendo camino hacia la participación protagónica de los y las estudiantes. Las producciones radiales se dieron a través de la misma estrategia usada en el semillero de participación en el que niñas y niños proponían temas de interés común y redactaban sus propios programas con asesorías de un adulto experto.

Luego de los talleres, inició el proceso de gestión para la apertura de un centro de interés en el que se ajustaran recursos fijos para los y las estudiantes interesadas en la conformación de la emisora escolar. Sin embargo, todo ello requiere de aprobación de presupuestos, espacios y equipos que a la fecha están siendo evaluados. Muchos de los niños y niñas que han participado a lo largo de la conformación del semillero, y después de la investigación misma, han continuado con el desarrollo de diferentes procesos tanto en bachillerato como en primaria para mejorar las dinámicas dadas en el entorno escolar y que definitivamente dan cuenta de una interiorización sobre su protagonismo como sujetos de derechos dentro y fuera del colegio.
Hoy podemos contar con las siguientes actividades:

- Lectura al descanso: un espacio gestado y dirigido por niños y niñas quienes adecuaron un salón para aquellos y aquellas que desearan leer en la hora de descanso; allí, establecieron las dinámicas dentro del salón, organizaron los libros según sus propios criterios de edad o intereses, asumieron un trabajo colectivo por y para los compañeros, lecturas colaborativas con los grados de primero, entre otros.

- Los gestores de espacios verdes: liderado por la representante estudiantil de primaria, quien ejecutó una campaña de cuidado del medio ambiente y reciclaje de botellas en las que debían rellenar con empaques plásticos que serían recolectados de manera gradual, instaurándolo con un grupo de compañeros y compañeras para la adecuación de espacios verdes embellecidos para el disfrute de todos. Los representantes al consejo estudiantil incluyeron a niños y niñas de primaria por primera vez en sus reuniones como ente autónomo en el cual establecieron las dinámicas y prioridades por sí mismos.

Debido a la situación de salud pública causada por la pandemia, estos avances han quedado sin movilización, al menos en lo que se refiere a la apropiación de los espacios y las propuestas. No obstante, se abrió una nueva posibilidad de continuar el proceso de formación sobre emisoras escolares, esta vez con la participación de dos maestros de la institución interesados en apoyar el fortalecimiento de la participación de niños y niñas. Además, con la posibilidad de crear redes con otras instituciones que inicien o fortalezcan sus procesos radiales y que puedan alimentar ese camino.

Es vital para los niños y niñas que los adultos seamos conscientes de la importancia que tienen sus voces en la tarea de transformar nuestras sociedades hacia la equidad, la paz y la participación ciudadana; pues ellos son hoy sujetos presentes, 
actuales, reflexivos, lectores de sus realidades y ejecutores de soluciones a dichas realidades.

\section{Referencias}

González, P. y Pulido, Y. (2019). Significaciones imaginarias sociales sobre participación de niños y niñas en la escuela para la cultura de paz.
Semillero de participación las voces del Cedid (tesis de grado maestría). Universidad Distrital Francisco José de Caldas, Colombia.

Rincón, C. (2013). Imaginarios sobre infancia, políticas públicas y prácticas pedagógicas (tesis de doctorado). Universidad Nacional Autónoma de México, México.

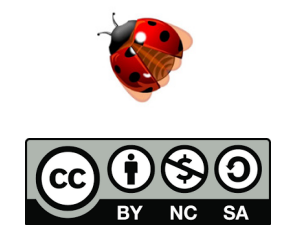

Esta obra está bajo licencia Creative Commons Atribución-NoComercial-Compartirlgual 4.0 Internacional 